\title{
Evaluation of immunization coverage among children aged 12-23 months in Surendranagar city
}

\author{
Darshan K. Mahyavanshi, Shashwat S. Nagar*, Mitali G. Patel, \\ S. S. Nagar, Shyamal K. Purani, Girija P. Kartha
}

Department of Community Medicine, CU Shah Medical College, Surendranagar, Gujarat, India

Received: 11 March 2013

Accepted: 12 April 2013

*Correspondence to:

Dr. Shashwat S. Nagar,

Email: ssn.9982@gmail.com

(C) 2013 Mahyavanshi DK et al.

This is an open-access article distributed under the terms of the Creative Commons Attribution License, which permits unrestricted use, distribution, and reproduction in any medium, provided the original work is properly cited.

\begin{abstract}
Background: Infectious diseases are a major cause of morbidity \& mortality in children. One of the most cost effective \& easy methods for child survival is immunization. In May 1974, the World Health Organization (WHO) officially launched a global immunization programme known as Expanded Programme of immunization (EPI) to protect all the children of the world against 6 Vaccine Preventable Diseases by the year 2000. It was later redesignated as Universal Immunization Programme (UIP) since 1985. The objectives of this study were to assess the dropout rate and primary immunization coverage of children aged 12-23 months in Surendranagar city and to know the various reasons for partially or not immunizing the child.
\end{abstract}

Methods: A community-based cross-sectional study. Thirty clusters were selected out of a total of 282 blocks of Surendranagar using the cluster sampling method. Cluster sampling method was used for sample selection and the proforma designed by UNICEF was used as a study tool. Sample size was 210 children ( 7 Children from each cluster) of aged 12-23 months. The obtained data were analyzed using appropriate statistical tests like $\mathrm{Z}$ test and $\mathrm{X}^{2}$ test.

Results: Out Of the 210 surveyed children, 121(57.62\%) were males and $89(42.38 \%$ ) were females. Immunization card was available for $69.52 \%$ of children and fully immunized were $70.47 \%$. Coverage was highest for BCG (95.71\%) followed by OPV3 (82.85\%), DPT3 $(79.52 \%)$ and lowest for measles $(75.23 \%)$. As far as the dropout rate is concerned, it was $21.39 \%, 10.21 \%$, and 9.37\% for BCG to measles, $\mathrm{DPT}_{1}$ to $\mathrm{DPT}_{3}$, and $\mathrm{OPV}_{1}$ to $\mathrm{OPV}_{3}$, respectively. Amongst the various reasons main reasons for dropout or unimmunization of children were ignorance in about $64 \%$ and lack of information regarding time, place and schedule $(21 \%)$.

Conclusions: Improvement should focus on reducing the dropout rate from DPT2/OPV2 to DPT3/OPV3 and improving coverage of measles and also Vitamin A.

Keywords: Immunization coverage, Cluster sampling, Dropout rate

\section{INTRODUCTION}

Infectious diseases are a major cause of morbidity \& mortality in children. One of the most cost effective \& easy method for child survival is immunization. In May 1974, the World Health Organization (WHO) officially launched a global immunization programme known as Expanded Programme of immunization (EPI) to protect all the children of the world against 6 Vaccine Preventable Diseases by the year 2000. It was later redesignated as Universal Immunization Programme (UIP) since 1985.
The current scenario depicts that immunization coverage has been steadily increasing but the average levels remain far less than desired. Still only $44 \%$ of infants in India are fully immunized as per NFHS-3 which is much less than the desired goal of achieving $85 \%$ coverage. $^{2}$

UNICEF report ranks India $49^{\text {th }}$ in child mortality. Nearly 2.4 million Indian Children perished due to pneumonia, diarrhea, measles, tetanus \& whooping cough. ${ }^{3}$

The present study was therefore conceptualized to evaluate the immunization coverage of children in the 
city and to suggest necessary interventions for its improvement.

\section{Aims \& Objectives}

1. To assess the dropout rate and primary immunization coverage of children aged 12-23 months in Surendranagar city and 2. To know the various reasons for partially or not immunizing the child.

\section{METHODS}

Study Design: It was a community-based cross-sectional study. All the blocks (282) in the city were enumerated \& from that 30 clusters were selected using the cluster sampling method.

Study Tool: Cluster sampling method was used for sample selection and the Proforma designed by UNICEF was used as a study tool. ${ }^{4}$

Sample Size: Nearly 210 children (7 Children from each cluster) of aged 12-23 months were selected for the study.

Statistical Analysis: The obtained data was analyzed using appropriate statistical tests like $\mathrm{Z}$ test and $\mathrm{X}^{2}$ test.

Following criteria was used for categorization of full, partial and no immunization. ${ }^{1}$

Full Immunization: Child 1-2 years of age, who received 3 doses of DPT \& OPV each, 1 dose to BCG \& measles each.

Partial Immunization: Child, who missed any 1 or more of above doses.

No immunization: Child who has not received even a single dose of vaccine.

\section{RESULTS}

A total of 210 children from 30 clusters were assessed for immunization coverage from Surendranagar city.

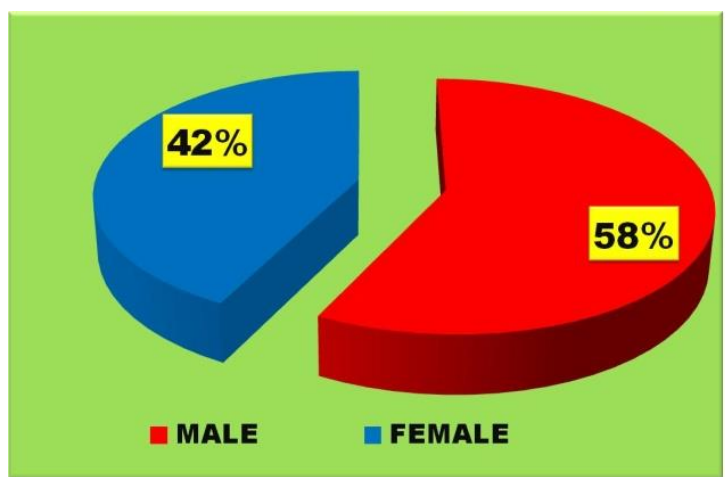

Figure 1: Distribution of the subjects sex wise $(\mathrm{N}=\mathbf{2 1 0})$.
The above figure shows that nearly $58 \%$ of the subjects were females.

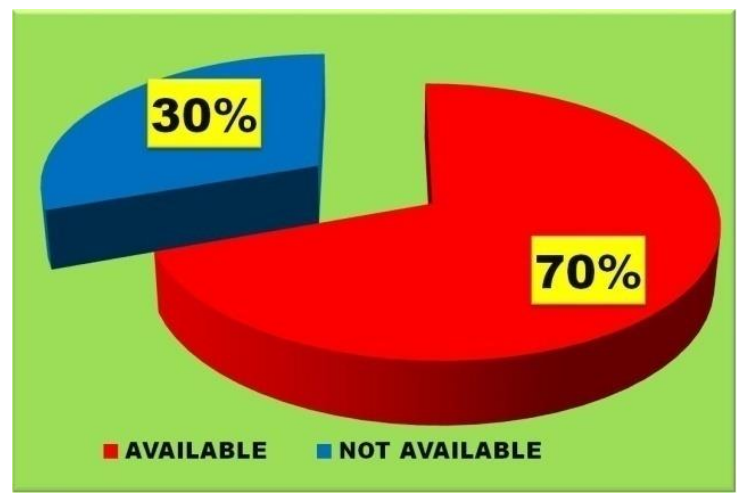

Figure 2: Distribution as per availability of immunization card $(\mathrm{N}=\mathbf{2 1 0})$.

The above figure shows that majority of the respondents $(70 \%)$ did have an immunization card at the time of visit.

Table 1: Table showing the present immunization status of subjects $(\mathrm{N}=\mathbf{2 1 0})$.

\begin{tabular}{|lll|}
\hline Vaccination & No. & Percentage (\%) \\
\hline BCG & 201 & 95.71 \\
\hline POLIO (zero dose) & 128 & 60.95 \\
\hline DPT-1 & 186 & 88.57 \\
\hline DPT-2 & 159 & 75.71 \\
\hline DPT-3 & 167 & 79.52 \\
\hline OPV-1 & 192 & 91.42 \\
\hline OPV-2 & 159 & 75.71 \\
\hline OPV-3 & 174 & 82.85 \\
\hline MEASLES & 159 & 75.71 \\
\hline VIT. A-1 & 151 & 71.90 \\
\hline VIT. A-2 & 98 & 46.66 \\
\hline VIT. A-3 & 44 & 20.95 \\
\hline Fully Immunized & 148 & 70.47 \\
\hline Partially Immunized & 53 & 25.24 \\
\hline Not Immunized & 09 & 4.29 \\
\hline
\end{tabular}

The above table shows that nearly $70 \%$ of the subjects were fully immunized and the remaining $25 \%$ partially immunized. Only about $4 \%$ of the subjects were completely unimmunized. 
Table 2: Immunization status comparison in males \& females $(\mathrm{N}=\mathbf{2 1 0})$.

\begin{tabular}{|l|llllll|}
\hline \multirow{2}{*}{$\begin{array}{l}\text { Status Of } \\
\text { Immunization }\end{array}$} & MALE & \multicolumn{3}{c}{ Sex } & FEMALE & \\
\cline { 2 - 7 } Fully Immunized & NO. & $\%$ & NO. & $\%$ & NO. & $\%$ \\
\hline Partially Immunized & 25 & 76.03 & 58 & 65.17 & 148 & 70.45 \\
\hline Unimmunized & 4 & 20.66 & 26 & 69.21 & 53 & 25.24 \\
\hline Total & 121 & 100 & 89 & 100 & 210 & 100 \\
\hline
\end{tabular}

Table 3: Table showing association of Immunization status with the social class of the subjects (Modified Prasad`s Classification 2009, $\mathrm{N}=\mathbf{2 1 0})^{5}$.

\begin{tabular}{|lll|llllll|l|}
\hline \multirow{2}{*}{ Social Class } & \multicolumn{3}{c}{ Fully Immunized } & \multicolumn{2}{c|}{ Partially Immunized } & \multicolumn{2}{c|}{ Not Immunized } & \multicolumn{2}{c|}{ Total } \\
\cline { 2 - 10 } & NO. & $\%$ & NO. & $\%$ & NO. & $\%$ & NO. & $\%$ \\
\hline Class 1, 2 \& 3 & 102 & 82.93 & 18 & 14.63 & 3 & 2.44 & 123 & 58.57 \\
\hline Class 4 \& 5 & 46 & 52.87 & 35 & 40.23 & 6 & 6.9 & 87 & 41.43 \\
\hline Total & 148 & 70.45 & 53 & 25.24 & 9 & 4.29 & 210 & 100 \\
\hline
\end{tabular}

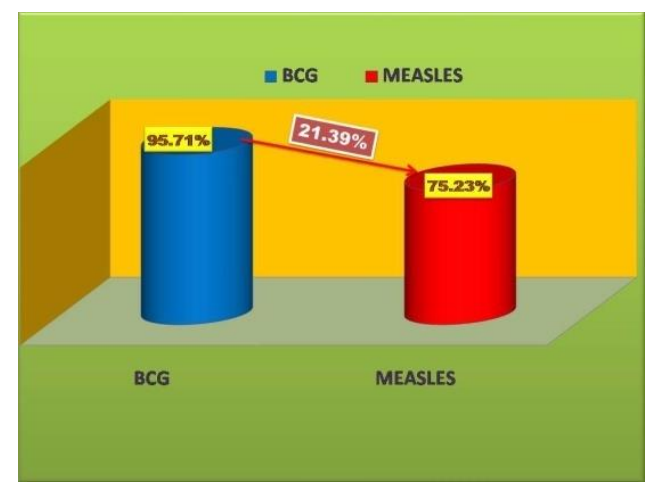

Figure 3a: Figure depicting the dropout rate from BCG to Measles $(\mathrm{N}=\mathbf{2 1 0})$.

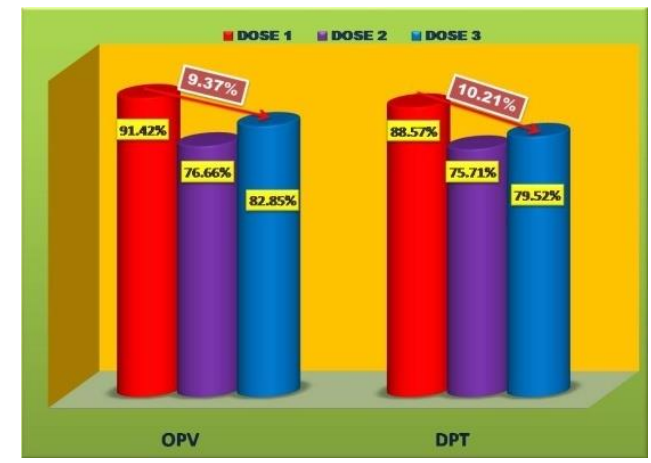

Figure 3b: Figure depicting the dropout rate from DPT 1-3 \& OPV 1-3 (N=210).
The dropout rate found out was $21.39 \%$ from BCG to measles. Nearly $96 \%$ of the individuals were vaccinated with BCG but for measles it was found to be $75 \%$.

The dropout rate from OPV1-3 is about $10 \%$ and similar dropout rate was found for DPT1-3.

The first dose of all vaccines like BCG, DPT and OPV had a very high coverage of nearly $90 \%$ and above.

It can be seen from the above table that the percentage of males who were fully immunized was much higher than their female counterparts (Table 2). Whereas in partially and unimmunized, both sexes showed similar picture.

When a significant difference was sought between the proportions of males \& females in all 3 groups using chi square test, the difference was not found statistically significant $\left(X^{2}=3.032, d f=2, p=0.2196\right)$.

The social class of the subjects was assessed using the Modified Prasad`s Classification 2009 with AICPI of Rs. $741 / .^{5}$

When the variables were associated, it was found that the higher social class had much higher immunization coverage as compared to lower social classes. The association was proved statistically significant using Chi square test $\left(X^{2}=41.051, \mathrm{df}=2, \mathrm{p}<0.0001\right)$. 
Table 4: Reasons for drop out or non immunization of children $(\mathrm{N}=\mathbf{2 1 0})$.

\begin{tabular}{|lll|}
\hline Reasons & No. & $\%$ \\
\hline $\begin{array}{l}\text { Child too young for } \\
\text { immunization }\end{array}$ & 10 & 16.13 \\
\hline $\begin{array}{l}\text { Unaware for need of } \\
\text { immunization }\end{array}$ & 41 & 66.13 \\
\hline $\begin{array}{l}\text { Unaware of the place \& } \\
\text { time of immunization }\end{array}$ & 21 & 33.87 \\
\hline Fear of side effects & 34 & 54.84 \\
\hline No faith in immunization & 08 & 12.9 \\
\hline Services not within reach & 26 & 41.94 \\
\hline $\begin{array}{l}\text { Family problems including } \\
\text { mother`s illness }\end{array}$ & 06 & 9.68 \\
\hline Child was ill & 12 & 19.35 \\
\hline Do not remember & 09 & 14.51 \\
\hline
\end{tabular}

The above table shows the importance of IEC activities for UIP as nearly $66 \%$ of the individuals were not aware of the need for immunization \& $55 \%$ felt the fear of adverse events following immunization (Table 4). About $42 \%$ felt that the services were too far away/ not within reach \& $33 \%$ not aware of date \& time of immunization, which re iterates the importance of strengthening outreach services. Nearly $17 \%$ had myths like child too young for immunization etc.

\section{DISCUSSION}

In a study conducted by Yadav $\mathrm{S}$ et al it was seen nearly $70 \%$ which is almost similar to present study. ${ }^{1}$ In the same study nearly $26 \%$ were partially immunized which is similar to present study. In the same study, the major reasons for non-immunization were ignorance $(80 \%)$ which is little higher than the present study $(60 \%)$.

In a study conducted by Sharma $\mathrm{R}$ et al, it was seen nearly $25 \%$ which is much lower to present study. ${ }^{2}$ In the same study nearly $52 \%$ were partially immunized which is much lower than present study. In the same study, BCG to measles dropout rates were $60 \%$ which was much higher than present study, where the dropout rates of the same were $22 \%$.

In MICS 1998, 300 children were assessed for immunization coverage and the rates were $75 \%, 76.3 \%$ and $51.3 \%$ for BCG, DPT3 and OPV3 respectively. In the present study the rates of the three were $96 \%, 80 \%$ and $82 \%$ respectively. This difference could be because of the better functionality of the UIP services in a large city like Surat. ${ }^{6}$

In this study fully immunized children were $70.47 \%$, whereas as per NFHS III \& DLHS III only (44\%, 54\%) children were fully immunized in India and $(45.2 \%$, $54.9 \%$ ) in Gujarat, but it was lower than the Surendranagar district ( $86 \%$ fully immunized) as per a report from CDHO office 2010-11. -9 $^{7-9}$

\section{CONCLUSION}

Improvement should focus on reducing the dropout rate from $\mathrm{DPT}_{2} / \mathrm{OPV}_{2}$ to $\mathrm{DPT}_{3} / \mathrm{OPV}_{3}$ and improving coverage of measles and also Vitamin A.

The remaining deficiencies can be taken care of by generating awareness among the community by holding mother's meetings and extensive IEC programs, inviting opinions and suggestions from them, and enhancing community participation.

\section{REFERENCES}

1. Yadav S, Mangal S, Padhiyar N, Mehta JP, Yadav BS. Evaluation of Immunization Coverage in Urban Slums of Jamnagar City. Indian J Community Med 2006;31:300.

2. Sharma R, Desai VK, Kavishvar A. Assessment of immunization status in the slums of surat by 15 clusters multi indicators cluster survey technique. Indian J Community Med 2009;34:152-5.

3. Massood A, Dwiwedi S, Singh G, Hassan MA, Singh A. Assessment of immunization status of children between 12-23 months in Allahabad district. National J Community Med 2011;2:346-8.

4. UNICEF proforma, www.iips.org.

5. Community Medicine with recent advances by A.H. Suryakantha. Modified Prasad`s Classification of 2009.

6. Reports on Multi Indicator Cluster Survey in slums of Surat city conducted by PSM Department, Govt. Medical College, Surat in assistance with UNICEF Gandhinagar (Gujarat), 1997, 1998.

7. National Family Health Survey (NFHS)-3 (20052006)-India, Gujarat.

8. District Level Household Surveys (DLHS)-3, (20072008) India, Gujarat.

9. Surendranagar district data sheet report 2010-11.

doi:10.5455/2319-2003.ijbcp20130610

Cite this article as: Mahyavanshi DK, Nagar SS, Patel MG, Nagar SS, Purani SK, Kartha GP.

Evaluation of immunization coverage among children aged 12-23 months in Surendranagar city. Int J Basic Clin Pharmacol 2013;2:286-9. 